\title{
The simulation of a Rankine based Waste Heat Recovery system for a heavy duty diesel engine
}

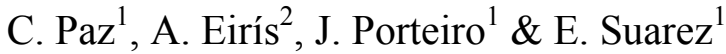 \\ ${ }^{1}$ Escuela de Ingeniería Industrial, University of Vigo, Spain \\ ${ }^{2}$ Centro Universitario de la Defensa, Escuela Naval Militar, Spain
}

\begin{abstract}
The enormous amount of waste heat that is rejected through the exhaust system in a modern engine is possibly the main source of energy yet to be converted into power on a conventional internal combustion engine. The groups of technologies exploiting this source of energy are normally called Waste Heat Recovery (WHR) systems. The most promising WHR technology under development is probably the low pressure Rankine cycle employing an organic working fluid. The strong interaction between the WHR system with the exhaust and cooling systems of the engine, combined with the inherent transient nature of the engines employed in transportation, makes the correct design, sizing and construction of its main components especially challenging. In this work, commercial 1-D software is employed to model the recovery system. The system consists of two boilers, one in the main exhaust line and another in the exhaust gas recirculation circuit. These boilers generate high pressure vapour that is expanded to obtain power. The low pressure vapour leaving the expander is used to preheat the high pressure liquid at the exit of the pump, while the cooling system of the engine is used to convert the low pressure, low temperature vapour into liquid in the condenser. Finally, a positive displacement pump is employed to heighten the pressure of the liquid. For this, R245-fa will be used as operating fluid. To build the model of the whole system, specific geometrical and material aspects of each main component are required. This information is based on state-of-the-art equipment and on experimental information available for the calibration of each subsystem. A parametric optimization of the main operational parameters of the WHR, is done to optimize the performance of the different systems and integration with the engine. Finally, the whole system is simulated under different load conditions of the engine to obtain its overall performance.

Keywords: Organic Rankine Cycle, automotive waste heat recovery.
\end{abstract}




\section{Introduction}

The concept of recovering wasted heat rejected by internal combustion is nothing new. Waste Heat Recovery (WHR) from very large diesel engines has been implemented with success and acceptance for industrial and marine application since the early 1970s when the first energy crisis broke out. Nowadays, motivated by the increase in fuel prices and stringent emission laws, large researching and development investments are devoted to extending WHR technologies to the automotive industry. Among the proposed solutions, the technologies based on the Organic Rankine Cycle (ORC) and thermoelectric material properties are the dominating ones [1]. ORC solutions provide higher efficiency than thermoelectric solutions in the conversion of low-grade heat sources (wasted heat, solar energy, geothermal energy, biomass energy and ocean energy) and have become the main research direction of engine WHR [2]. Organic fluids are preferred to water when the required power is limited and the heat source temperature is low, as these fluids often require lower heat for vaporization and can better follow the heat source to be cooled, thus reducing temperature differences and, therefore, irreversibility at the evaporator.

Despite the success in stationary engines, the cost and complexity of waste heat recovery systems have blocked their implementation in passenger cars, light commercial vehicles and heavy duty engines. Light duty passenger vehicles present tight packaging constraints and transient operation conditions that pose a challenge for WHR implementation in the near future. The best opportunity for successful application of waste heat recovery technology is for Heavy Duty Diesel Engines (HDDE). In on-highway applications, HDDE are used for heavyweight trucks and buses under highly loaded duty cycles with a lot of time spent at full load.

In this paper a numerical study is conducted to investigate the potential improvement of the overall efficiency of a HDDE equipped with a Rankine bottoming cycle and to remark about the requirements of the components of the system.

\subsection{Heavy Duty Diesel Engine model}

In order to considerer representative operating conditions of a HDDE a virtual engine model supplied by GT-Suite was used in this study. The engine model was calibrated with measure engine data from a researching program aimed to reduce the fuel consumption and $\mathrm{CO} 2$ emissions of heavy duty long haul trucks. So the engine model is assumed to be representative of the HDDE class. The performance maps of the virtual engine model are published in [3]. The virtual engine model has technical characteristics in common with heavy duty truck engines that meet 2007 emissions requirements. High pressure loop cooled exhaust gas recirculation (EGR) is used to control NOx emissions, while a diesel particulate filter system is used to control PM. The basic characteristics of the engine are summarised in table 1. 
Table 1: Engine specifications.

\begin{tabular}{|l|c|c|}
\hline Item & Parameter & Unit \\
\hline Displacement & 11.7 & liters \\
\hline Number of cylinders & 6 & \\
\hline Valves per cylinder & 4 & \\
\hline Fuel injection system & Common rail & \\
\hline Engine speed range & {$[800,2000]$} & rpm \\
\hline Maximum torque & $1825 @ 1400$ & Nm@rpm \\
\hline
\end{tabular}

The main sources of waste heat are identified in figure 1. Table 2 shows the heat rate and the temperature for each of the four waste heat sources when the engine is operating at high load near the point of highest thermal efficiency. Exergy considerations clarify that EGR and the tailpipe exhaust gases are the best sources for heat recovery.

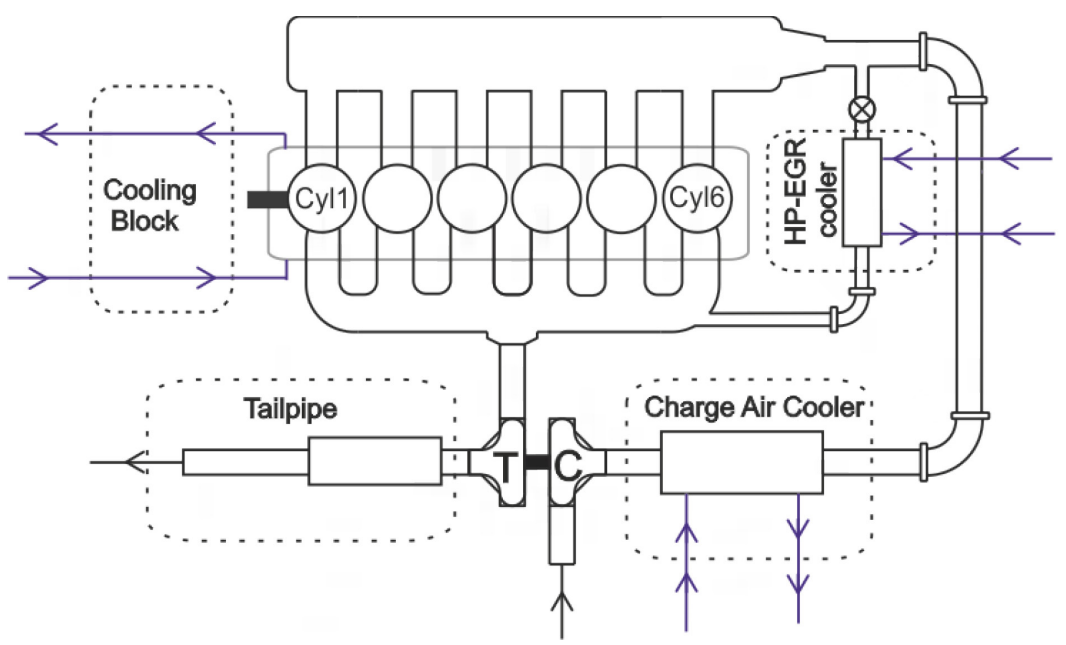

Figure 1: Sources of waste heat.

Table 2: Energy balance [4].

\begin{tabular}{|l|c|c|}
\hline \multicolumn{1}{|c|}{ Energy Flow Path } & $\begin{array}{c}\text { \% of Total } \\
\text { Fuel Energy }\end{array}$ & $\begin{array}{c}\text { Temperature } \\
\left({ }^{\circ} \mathrm{C}\right)\end{array}$ \\
\hline Mechanical energy & $40-42$ & \\
\hline Tailpipe & $19-21$ & 400 \\
\hline Cooling Block & $17-19$ & 90 \\
\hline EGR Cooler & $10-12$ & 540 \\
\hline Charge Air Cooler & $8-10$ & 170 \\
\hline Other (Radiation) & $1-3$ & varies \\
\hline
\end{tabular}




\section{WHR model development}

Modelling of WHR systems can be tackled by two different approaches: Steadystate thermodynamic models and one dimensional models. Models of the first group are suitable in the early state of the development process for working fluid selection according to the temperature level of heat sources recovered. One dimensional models solve the mass, momentum and energy balance equations in a domain of discretized circuits by integrating in time. The two phase state is resolved by a homogeneous model using the averaged property between the liquid and the vapour state. One dimensional models provide the transient response of the system and are required for dynamic control strategies under transient heat source conditions.

The WHR model based in the ORC is built in the framework of GT-Suite commercial software. GT-Suite has multiphysic libraries (flow, thermal, mechanical, control, etc.), Refprop fluid properties database and a friendly graphical user interface that facilitates the model development process. The WHR model is built by interconnecting the different components defining the system: heat exchangers, pump, expander, receiver, pipes and junctions. The process of converting complex geometric components into one-dimensional models requires physical understanding and technical skills. For this purpose, the model components are built based on existing equipment with available experimental data. The model parameters setup are tuned to better fit the performance maps of each component.

\subsection{System architecture}

Having identified the main sources of potential waste heat recovery, it seems reasonable to study ORC systems with boilers placed in the HP-EGR loop and in the tailpipe. Figure 2 shows the serial and parallel layout. The parallel configuration enables us to control the working fluid flow ratio between EGR-boiler and TP-boiler. The serial configuration provides better heat recovery efficiency and is the one selected in this research.
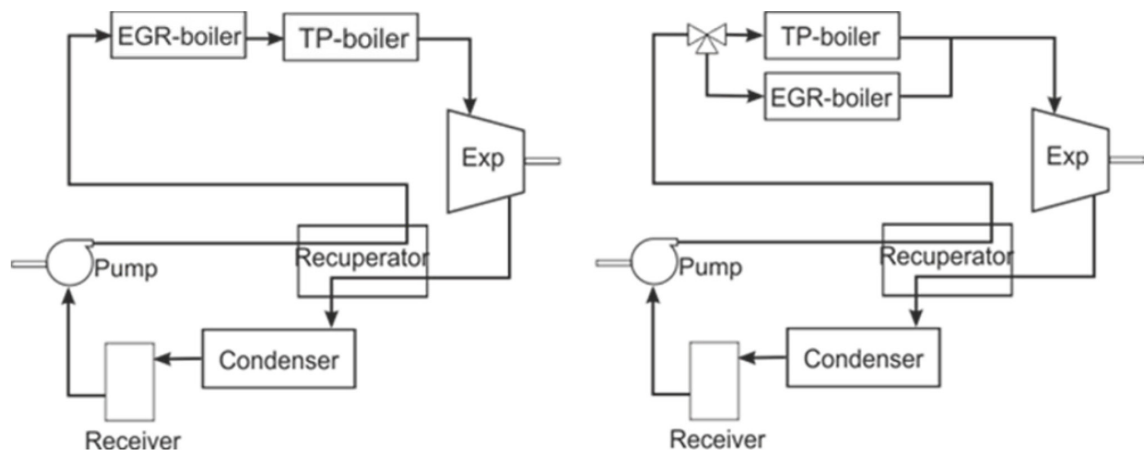

Figure 2: Serial and parallel layouts. 
In order to increase the ORC efficiency, a recuperator is used so that the heat of the expanded vapour, which is still superheated, can be employed to preheat the working fluid after the condenser and bring it closer to saturated fluid.

\subsection{Working fluid selection}

While fluid selection studies in the scientific literature cover a broad range of working fluids, only a few fluids are actually used in engine WHR system. In this study the R245fa was selected as the working fluid due to its reasonable cycle output work and mild condensation pressure. In order to avoid air infiltrations in the cycle, high condensing pressures are advisable. Low temperature organic Rankine fluids such as R245fa meet this requirement since they condensate at a pressure higher than the atmospheric pressure. There are other requirements for the working fluid to be selected in engine WHR applications. For instance, working fluids with small latent heat are always selected in the diesel engine WHR system to insure the superheated state of the vapour before the expanding process. A high thermal stability temperature and a low freezing point are also desirable properties for the working fluid.

Panesar et al. [5] conducted an investigation to elaborate a fluid ranking for WHR applied to HDDE. Since no working fluid can be flagged as optimal for engine waste heat recovery, the study of the working fluid candidates should be integrated into the design architecture of any ORC system.

\subsection{Expander and pump}

Performance of the ORC system strongly correlates with that of the expander. Two main types of machines can be distinguished: the turbo and positive displacement types. Similar to refrigeration applications, displacement type machines are more appropriate to the small-scale ORC units, because they are characterized by lower flow rates, higher pressure ratios and much lower rotational speeds than turbo-machines. While technically mature, turbomachines are available on the market for larger ORC units, almost all positive displacement expanders that have been used up to now are prototypes, often derived from existing compressors. Positive displacement expanders are a good substitute to turbomachines for low output applications, as they can tolerate the presence of a liquid phase during expansion, and they show a good isentropic efficiency. Also, their lower rotating speed makes them easier to couple to the engine. Therefore, in general, turbine expanders are preferred when the waste heat recovered is converted into electrical energy, while the positive displacement expanders are considered more appropriate for combining mechanical output directly to the crankshaft.

The working fluid pump is a rotary vane pump which was selected because it is appropriate for low flow rates with high pressure. Although the vane pump is a positive displacement pump, it is a rotary pump and handles two-phase flow and cavitation better than other types of positive displacement pumps and centrifugal 
pumps. The expander chosen in this work is of a volumetric type, with a total displacement of $1.25 \mathrm{l}$. It was modelled by the equivalent positive displacement expander whose volumetric efficiency was imposed as the inverse of the instantaneous pressure ratio.

\subsection{Heat exchangers}

In the framework of 1-dimensional fluid dynamics solver a basic model of the heat exchanger can be developed by means of convection connectors and thermal masses component. By means of convection connector is possible to incorporate heat transfer correlations from the literature and thermal masses components allow taking into account thermal inertias and conduction resistances. Figure 3 shows an example of the kind of discretization employed in the simulation of the heat exchangers.

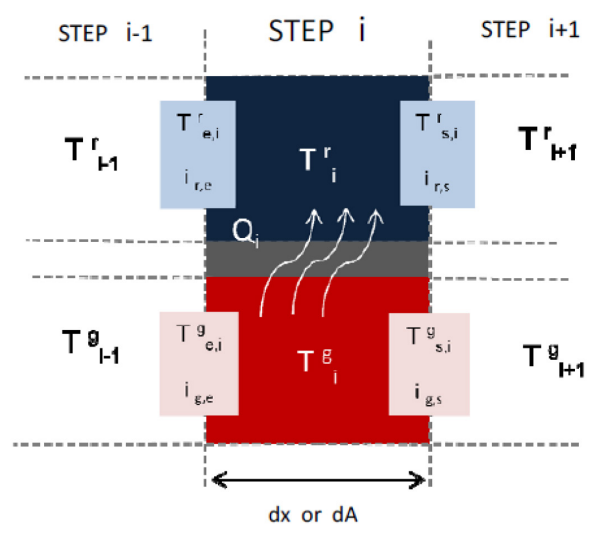

Figure 3: Discretization for heat exchanger models (g: gas, r: coolant).

\subsubsection{EGR boiler}

The EGR evaporator considered is a shell/tube heat exchanger, which removes heat from the gases being recirculated to the engine for emission reduction. The tube bundle consists of 100 tubes with a diameter of $10 \mathrm{~mm}$ and a length of $400 \mathrm{~mm}$. The outer shell has a diameter of $150 \mathrm{~mm}$. The working fluid flows inside the tubes while the EGR gases passes through the shell. Additional EGR cooling may be necessary but it is not including in this work. In this work, to keep the engine unaffected by the tests being performed on the OCR system, the presence of this additional cooler was considered that produced a constant EGR temperature of $150^{\circ} \mathrm{C}$.

\subsubsection{Tailpipe boiler}

The tailpipe evaporator considered is a shell/tube heat exchanger, which removes heat from the hot exhaust gases. The tube bundle consists of 100 tubes with a diameter of $10 \mathrm{~mm}$ and a length of $300 \mathrm{~mm}$. The working fluid flows inside the tubes while the exhaust gases passes through the shell. 


\subsubsection{Recuperator}

This heat exchanger improves the efficiency of the cycle by allowing heat transfer from the high temperature low pressure side to the low temperature high pressure side. Here, the recuperator is also modelled as a shell/tube heat exchanger of $20 \mathrm{~mm}$ diameter and $100 \mathrm{~mm}$ length.

\subsubsection{System integration}

Once the components models are created, the model system is assembled by inserting the connecting pipes. Figure 4 shows a detail of the serial ORC system implemented in the simulation software.

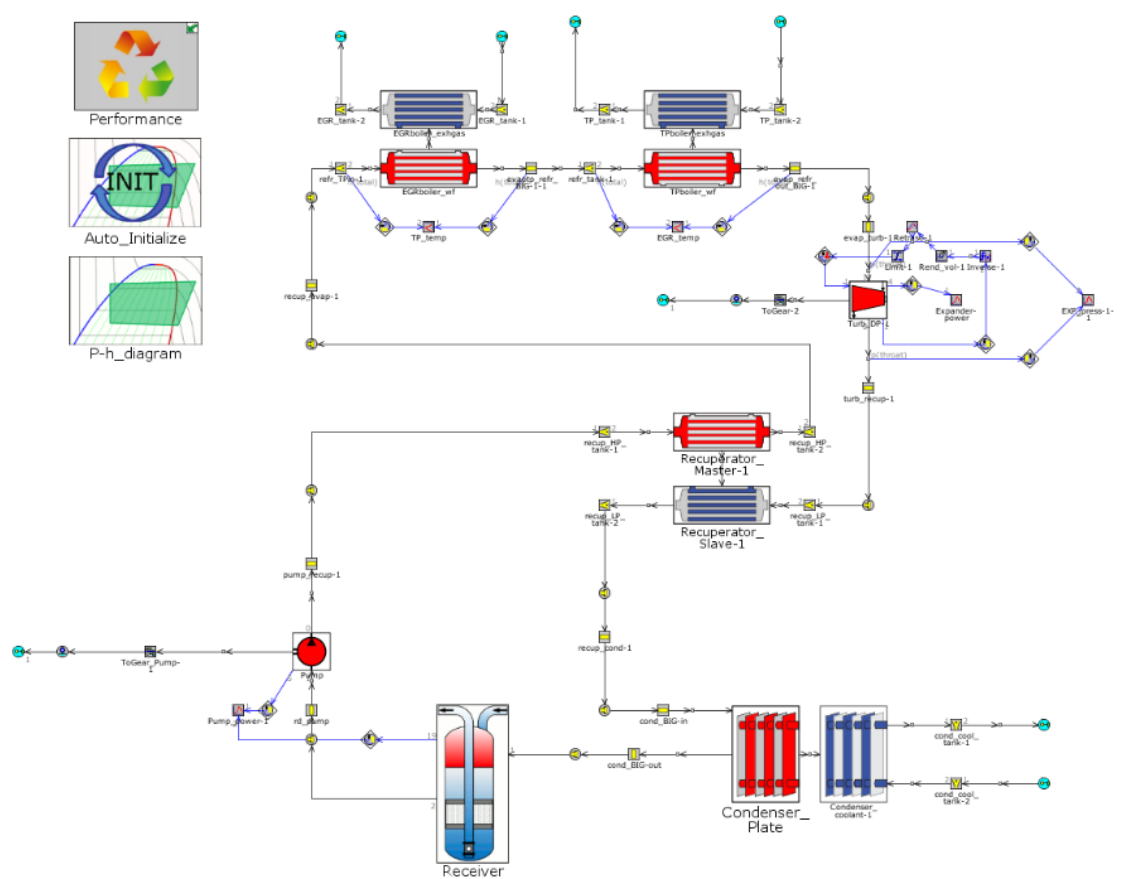

Figure 4: Serial ORC model.

\section{Results and discussion}

The WHR system performance was evaluated at 3 of the 13 mode points of the European Stationary Cycle (A75, B75 and C75). Figure 5 shows the brake torque at full load and the location of the three points considered to evaluate the effects of the WHR system in the engine performance. For comparison purposes, the three selected points employ a $20 \%$ ratio of EGR. 


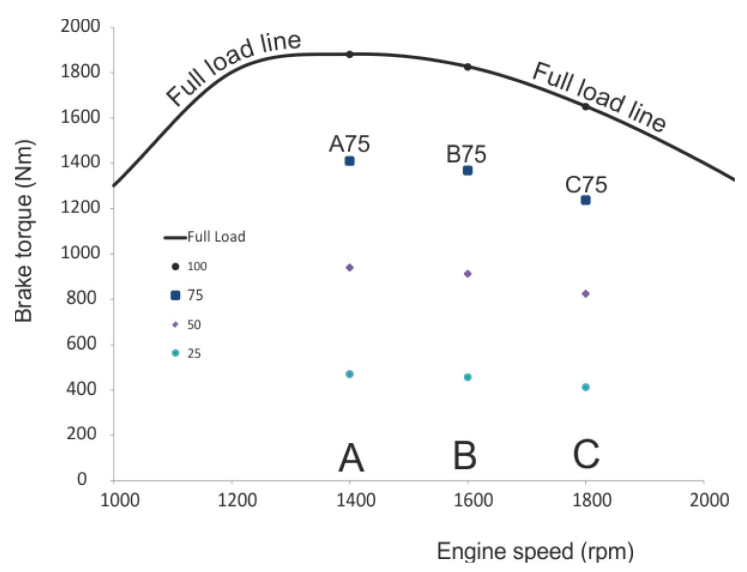

Figure 5: Brake-speed map and ESC points.

Table 3: WHR operation parameters.

\begin{tabular}{|c|c|c|c|c|c|}
\hline & & & A75 & B75 & $\mathbf{C 7 5}$ \\
\hline \multirow{2}{*}{ Engine } & Speed & $\mathrm{rpm}$ & 1400 & 1600 & 1800 \\
\hline & Brake Power & $\mathrm{kW}$ & 205 & 255 & 305 \\
\hline \multirow{6}{*}{ EGR- boiler } & Gas mass flow rate & $\mathrm{kg} / \mathrm{h}$ & 265.7 & 303.9 & 338.4 \\
\hline & Gas inlet temperature & ${ }^{\circ} \mathrm{C}$ & 630.1 & 696.3 & 758.9 \\
\hline & Gas outlet temperature & ${ }^{\circ} \mathrm{C}$ & 185.7 & 249.3 & 271.0 \\
\hline & WF inlet temperature & ${ }^{\circ} \mathrm{C}$ & 90.5 & 101.0 & 104.5 \\
\hline & WF outlet temperature & ${ }^{\circ} \mathrm{C}$ & 157.5 & 172.8 & 184.3 \\
\hline & Heat exchange & $\mathrm{kW}$ & 38.4 & 45.0 & 55.6 \\
\hline \multirow{6}{*}{ TP-boiler } & Gas mass flow rate & $\mathrm{kg} / \mathrm{h}$ & 1107.9 & 1272.9 & 1424.5 \\
\hline & Gas inlet temperature & ${ }^{\circ} \mathrm{C}$ & 482.2 & 550.0 & 614.7 \\
\hline & Gas outlet temperature & ${ }^{\circ} \mathrm{C}$ & 422.1 & 477.5 & 529.3 \\
\hline & WF inlet temperature & ${ }^{\circ} \mathrm{C}$ & 157.5 & 172.8 & 184.3 \\
\hline & WF outlet temperature & ${ }^{\circ} \mathrm{C}$ & 231.9 & 236.8 & 236.0 \\
\hline & Heat exchange & $\mathrm{kW}$ & 21.2 & 30.0 & 40.5 \\
\hline \multirow{7}{*}{ Expander } & Speed & $\mathrm{rpm}$ & 1050 & 1200 & 1350 \\
\hline & WF inlet temperature & ${ }^{\circ} \mathrm{C}$ & 231.9 & 236.8 & 236.0 \\
\hline & WF outlet temperature & ${ }^{\circ} \mathrm{C}$ & 203.4 & 206.2 & 216.6 \\
\hline & Inlet pressure & bar & 11.3 & 20.1 & 19.2 \\
\hline & Outlet pressure & bar & 2.3 & 2.4 & 2.5 \\
\hline & Pressure ratio & & 4.91 & 8.4 & 7.7 \\
\hline & Power & $\mathrm{kW}$ & 9.75 & 17.8 & 26.6 \\
\hline \multirow{3}{*}{ Condenser } & WF inlet temperature & ${ }^{\circ} \mathrm{C}$ & 60.6 & 64.3 & 67.7 \\
\hline & WF outlet temperature & ${ }^{\circ} \mathrm{C}$ & 31.7 & 37.9 & 39.3 \\
\hline & Heat exchange & $\mathrm{kW}$ & 43.5 & 51.3 & 61.5 \\
\hline \multirow{3}{*}{ Cycle } & WF mass flow rate & $\mathrm{kg} / \mathrm{h}$ & 751.2 & 763.2 & 903.0 \\
\hline & Total heat rejection & $\mathrm{kW}$ & 59.6 & 75.0 & 96.1 \\
\hline & Efficiency & $\%$ & 16.4 & 23.7 & 27.7 \\
\hline
\end{tabular}


Table 3 summarises the results of the study. Some data concerning the performance of the system and its suitability for the application to this engine can be derived from them. As shown, the C75 point showed the highest WHRS efficiency probably due to the higher temperature level of the exhaust gases, while the condenser chosen seems to have enough capacity to keep the pressure of the system and hence the condensation temperature low.

Table 4: WHR operation parameters.

\begin{tabular}{|l|c|c|c|c|c|c|}
\hline & N (rpm & \multicolumn{2}{|c|}{ Brake Power $(\mathrm{kW})$} & \multicolumn{3}{|c|}{ BSFC (g/kW-h) } \\
\hline & & Engine & WHR-Serial & Engine alone & Engine + WHRS & BSFC \\
\hline A75 & 1400 & 205 & 9.75 & 238.0 & 226.7 & 11.3 \\
\hline B75 & 1600 & 255 & 17.8 & 246.2 & 229.0 & 17.2 \\
\hline C75 & 1800 & 305 & 26.6 & 254.9 & 232.7 & 22.2 \\
\hline
\end{tabular}

In table 4, the BSFC improvement is shown, which is in accordance with the potential saving achievable with this technology based on available references. The fuel savings obtained are $4.8 \%$ for the A75, $7.0 \%$ for B75 and $8.7 \%$ for the C75 point.

\section{Conclusions}

An Organic Rankine Cycle coupled to an 11.7-litre Heavy Duty Diesel Engine has been modelled and simulated with the commercial 1-D code GT-Suite. The Working Fluid (WF) chose was R245FA which is a typical high-pressure WF in this kind of applications. The system was simulated at three different points of operation of the engine leading to fuel saving between $4.8 \%$ of the lowest power point to $8.7 \%$ of the highest.

Also, the 1-D simulation proved to be a useful tool for the study of the coupling of this kind of Waste Heat Recovery Systems, at an affordable computational cost and in a reasonable time. For instance, the variation of the geometrical aspects of the main components, the change in the Working Fluid, control strategies, etc. which can be very difficult to test in an experimental facility can be easily tested with this methodology. However, the previous calibration of each of the components and the experimental verification of some of the results can never be omitted.

\section{References}

[1] V. Dolz, R. Novella, A. García \& J. Sánchez, HD Diesel engine equipped with a bottoming Rankine cycle as a waste alheat recovery system. Part 1 : Study and analysis of the waste heat energy. Applied Thermal Engineering, 36, pp. 269-278, 2012. 
[2] C. Sprouse III, C. Depcik, Review of organic Rankine cycles for internal combustion engine exhaust waste heat recovery. Applied Thermal Engineering, 51, pp. 711-722, 2013.

[3] Q. Xin, Diesel engine system design. Woodhead publishing.

[4] A. Brown et al., Technologies and approaches to reducing the fuel consumption of medium and heavy duty vehicles, National Academic Press, 2010.

[5] A.S. Panesar, R.E. Morgan, N.D.D Miche \& M. R. Heikal, An investigation of bottoming cycle fluid selection on the potential efficiency improvement of a Euro 6 heavy duty diesel engine. 